\title{
COMPARISON OF SELECTED AGRICULTURE UNIVERSITIES IN EUROPE ON BASIS OF ANALYSIS OF ACADEMIC OUTPUT
}

\author{
Adrian Knapczyk, Slawomir Francik, Marek Wrobel, Krzysztof Mudryk \\ University of Agriculture in Krakow, Poland \\ adrian.knapczyk91@gmail.com, slawomir.francik@urk.edu.pl
}

\begin{abstract}
The purpose of this work was to collate selected agriculture universities in Europe on the basis of academic output. This analysis was performed with the data from the Web of Science Core Collection database for the period 2009-2016. Selected universities are: Wageningen University \& Research (NLD - WUR), Swedish University of Agricultural Sciences (SWE - SUA), Norwegian University of Life Sciences (NOR NUA), Mendel University in Brno (CZE - MUA), Czech University of Life Sciences Prague (CZE - CULS), Slovak University of Agriculture Nitra (SVK - SLUA), Estonian University of Life Sciences (EST - EULS), Latvia University of Life Sciences and Technologies (LVA - LLU), SGGW - Warsaw University of Life Sciences (POL - WULS), University of Agriculture in Krakow (POL - KUA), Poznań University of Life Sciences (POL - PULS), Wrocław University of Environmental and Life Sciences (POL - WUELS), University of Life Sciences in Lublin (POL - LULS). Research methodology was performed in three steps: 1)searches in the Web of Science Core Collection database of standardized institutional names of selected academic institutions; 2) downloading selected scientific documents that were published in the WoS CC for standardized institutional names of selected academic institutions in the years 2009-2016; 3) loading data from the WoS CC database into the InCites: Benchmarking \& Analytics tool and analyzing selected indicators of academic output. In terms of employee publication activity, two groups can be distinguished: I - The Netherlands, Sweden, Norway and the Czech Republic, II - other universities. For all the analysed universities, both the number of publications and their quality increased over time, which proves the continuous scientific development of employees.
\end{abstract}

Key words: bibliometric analysis, scientometric, literature review, university evaluation.

\section{Introduction}

As in many different areas of human activity, various evaluations are carried out for scientific activities, as well. Among others, various university rankings are being developed (Academic Ranking of World Universities (ARWU), QS World University Rankings, THE - Times Higher Education World University Ranking, etc.). Polish universities occupy very distant positions in these rankings. It seems that one of the possibilities of comparing an agricultural university is to compare the number of publications in the most important scientific journals (indexed in JCR) and bibliometric indicators for various universities calculated on this basis. A comparison of universities is aimed at determine the quality of higher education institutions in individual countries. The result of such a comparison is the classification, which can be used to stimulate competition between research centers, distribution of financial resources and other.

The analysis of document sets is possible thanks to the growing number of bibliometric analysis tools. Bibliometry was first defined by Pritchard in 1969 as a mathematical and statistical method for analysing scientific achievements. One of the greatest advantages of this technique is the objective quantitative analysis of literature data based on measurable, objective, consistent and accessible data. Bibliometry is perfect for comparing scientific entities. Due to the wide diversity of universities around the world, analyses are often carried out for given regions. Scientists from all over the world undertake such analyses for a long time [1-7]. Apart from comparisons, such analyses allow us to determine trends in given scientific disciplines and identify major research topics and discoveries in the global network of knowledge. This is underlined by many authors of scientific publications. Bibliometric studies are widely used in the analysis of research trends [8-12].

\section{Materials and methods}

The aim of the paper was to compare leading science universities in Europe in the period between 2009 and 2016. The analysis was based on the following indicators: number of documents indexed on Web of Science - Core Collection (WoS-CC), average number of document citations, the percentage of documents published in IF journals compared to all WoS-CC documents and the number of documents published in particular journal quartiles. 
Selected universities of natural sciences are: Wageningen University \& Research (NLD - WUR), Swedish University of Agricultural Sciences (SWE - SUA), Norwegian Uniwersity of Life Sciences (NOR - NUA), Mendel University in Brno (CZE - MUA), Czech University of Life Sciences Prague (CZE - CULS), Slovak University of Agriculture Nitra (SVK - SLUA), Estonian University of Life Sciences (EST - EULS), Latvia University of Life Sciences and Technologies (LVA - LLU), SGGW - Warsaw University of Life Sciences (POL - WULS), University of Agriculture in Krakow (POL KUA), Poznań University of Life Sciences (POL - PULS), Wrocław University of Environmental and Life Sciences (POL - WUELS), University of Life Sciences in Lublin (POL - LULS).

It should be emphasised that two universities can be found in the Academic Ranking of World Universities (ARWU): Wageningen University \& Research between 100-150, Swedish University of Agricultural Sciences between 200-300.

The research methodology used the following stages:

1. Search in the Web of Science - Core Collection (WoS-CC) database for unified names of selected scientific institutions.

2. Downloading various scientific documents published in the WoS-CC for unified names of selected scientific institutions in the period between 2009 and 2016.

3. Loading data from the WoS-CC database into the InCites testing tool: Benchmarking \& Analytics and analysis of selected scientific achievement indicators.

InCites Benchmarking \& Analytics software is an advanced analytical tool offered by Claritive Analytics. A test access to this tool was available from 6 November to 6 December 2017 as part of the Virtual Library of Science. InCites B\&A offers the possibility of creating reports on scientific achievements and activity (scientific institutions, researchers), comparing sources of funding for selected research areas or institutions, identifying trends in selected research areas and many others. The platform was used to analyse the following indicators: number of documents in the WoS-CC and number of documents in the WoS-CC per employee. The percentages of documents published in Impact Factor journals and the number of publications published in journals in a particular quartile were also analysed.

\section{Results and discussion}

Figure 1 shows the number of documents published on the WoS-CC. There is an upward trend for all the universities analysed. The employees of NLD-WUR published in greatest numbers - from 2,300 documents (2009) to 3,300 documents (2015-2016). Another outstanding university is SWESUA, which employees published from 1200 documents (2009) to 1700 documents (2016). Employees of other universities published from 120-600 (2009) to 225-850 (2016) documents.

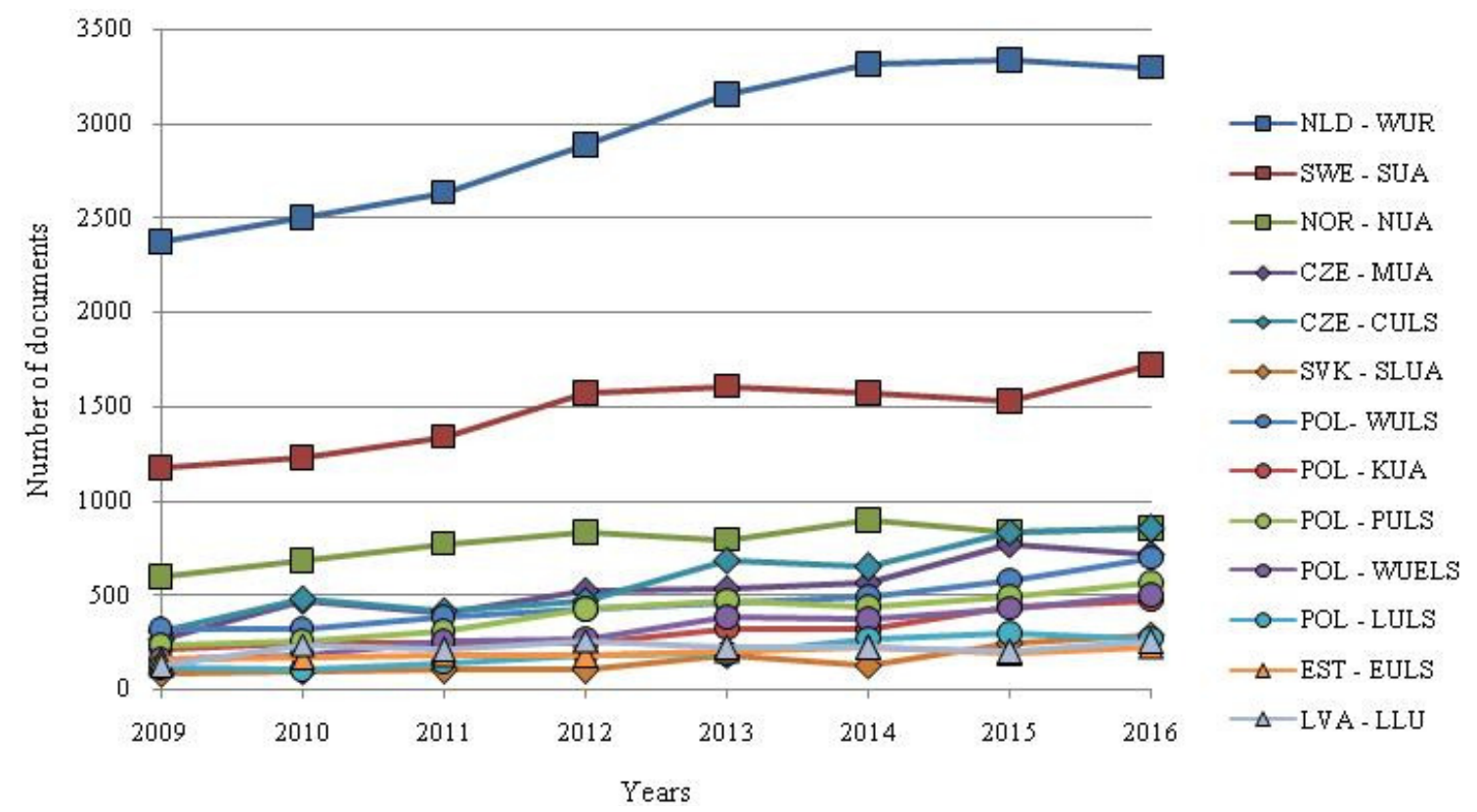

Fig. 1. Number of documents on WoS-CC 
Figure 2 shows the number of documents indexed on the WoS-CC per employee. The number of employees was estimated on the basis of data published publicly by research centres. Analysing the presented graph, two periods can be distinguished: 2009-2014 and 2015-2016. Between 2009 and 2016, two groups of universities are clearly visible. The first is CZE-MUA, NLD-WUR, SWE-SUA and NOR-NUA. The other group includes other research centres. In the other period (2015-2016), the group of universities mentioned above was joined by CZE-CULS.

Comparing 2016 with 2009, the average increase in the number of publications for the analysed universities was over $200 \%$. The highest growth was recorded by SVK-SLUA (350 \%).

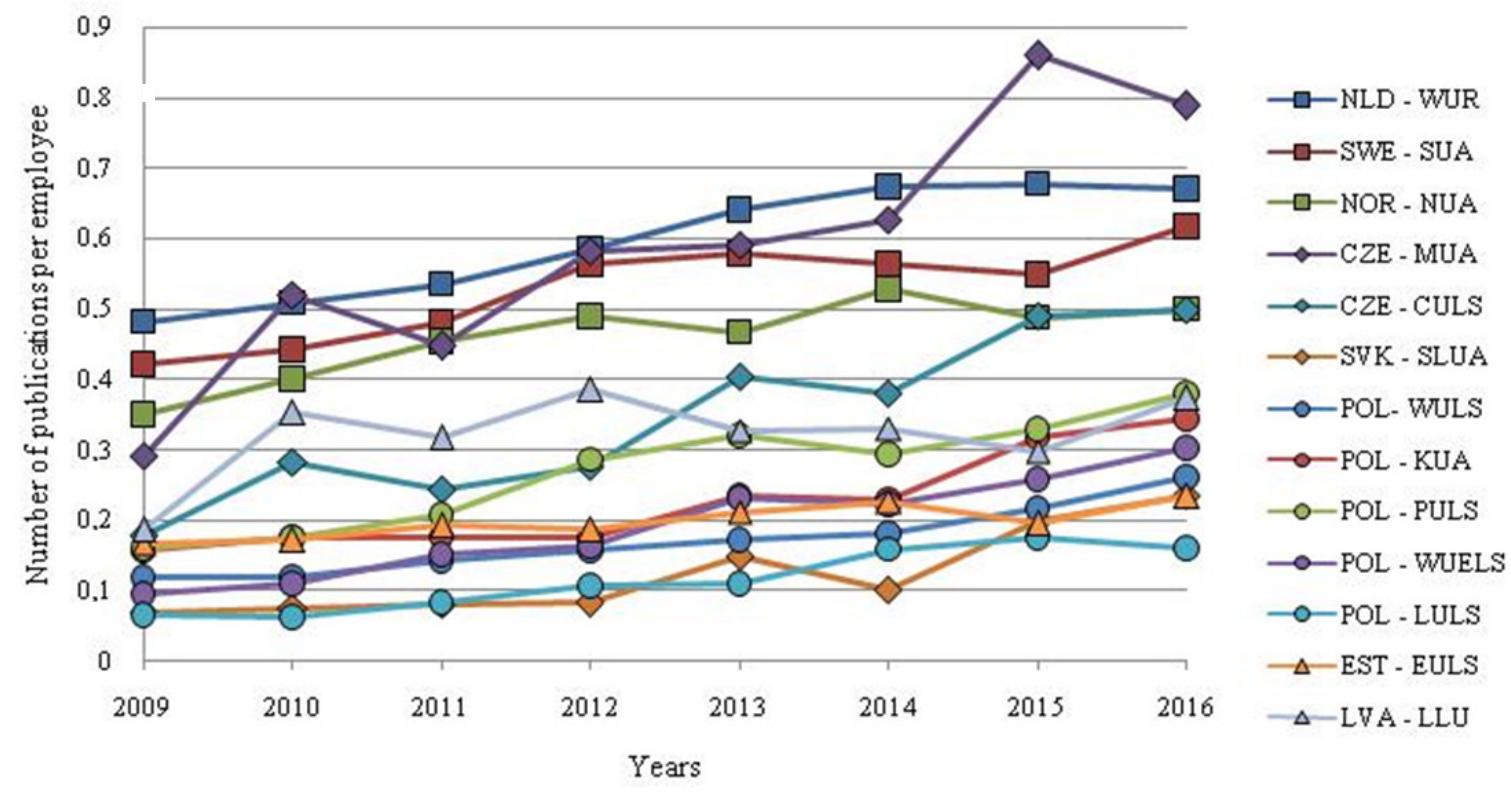

Fig. 2. Documents on WoS-CC per one university employee

Another analysed indicator is the average number of publication citations over the considered period. Older publications obviously have a higher average number of citations. Two groups of universities can be distinguished. The first with a larger number of citations (NLD-WUR, SWE-SUA, NOR-NUA and EST-EULS) and the other with a smaller number of citations (other universities). The older the publications, the clearer the difference between the groups.
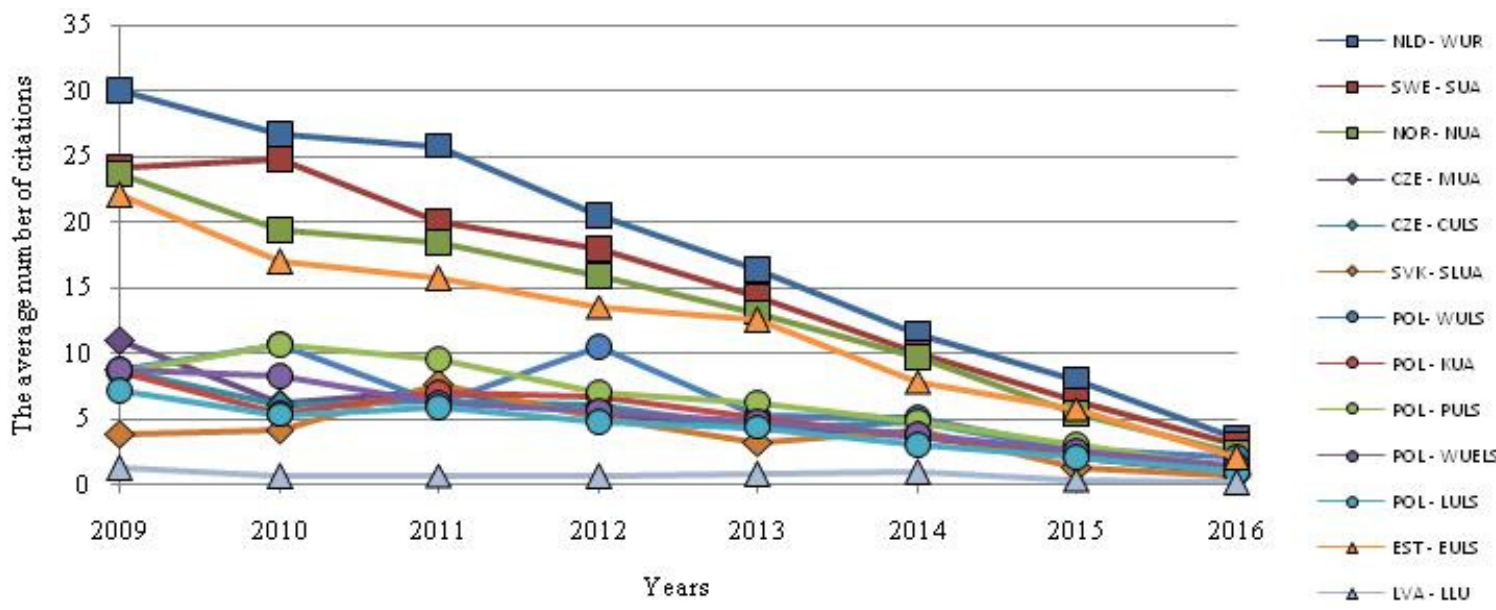

Fig. 3. Average number of citations

Figure 4 shows the percentage of documents published in the IF journals for all documents published on the WoS-CC. It shows that universities from the Netherlands, Sweden, Norway and Poland maintain a minimum publication rate of $70 \%$ throughout the analysis period. Universities from the Czech Republic and Slovakia publish within the range of 30-75\% depending on the year. In this indicator, Latvia's university differs markedly, as it publishes articles in IF journals at the level of $5-15 \%$. 


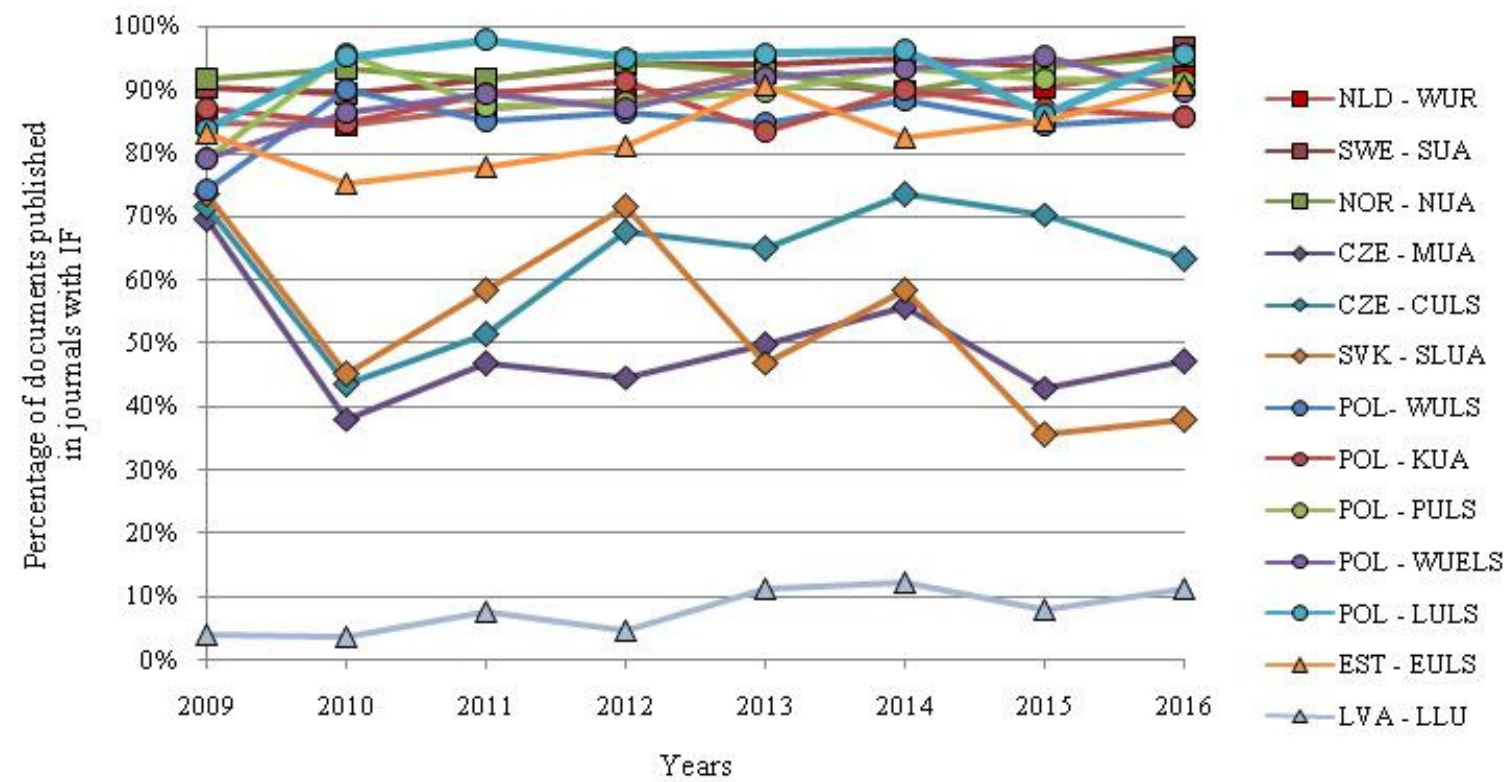

Fig. 4. Percentage of documents published in journals with IF for all WoS documents

Figure 5 shows the percentage share of conference materials indexed on WoS-CC and publications published in the JCR in Q1-Q4 quartiles for the years 2009-2012 and 2013-2016.

a)
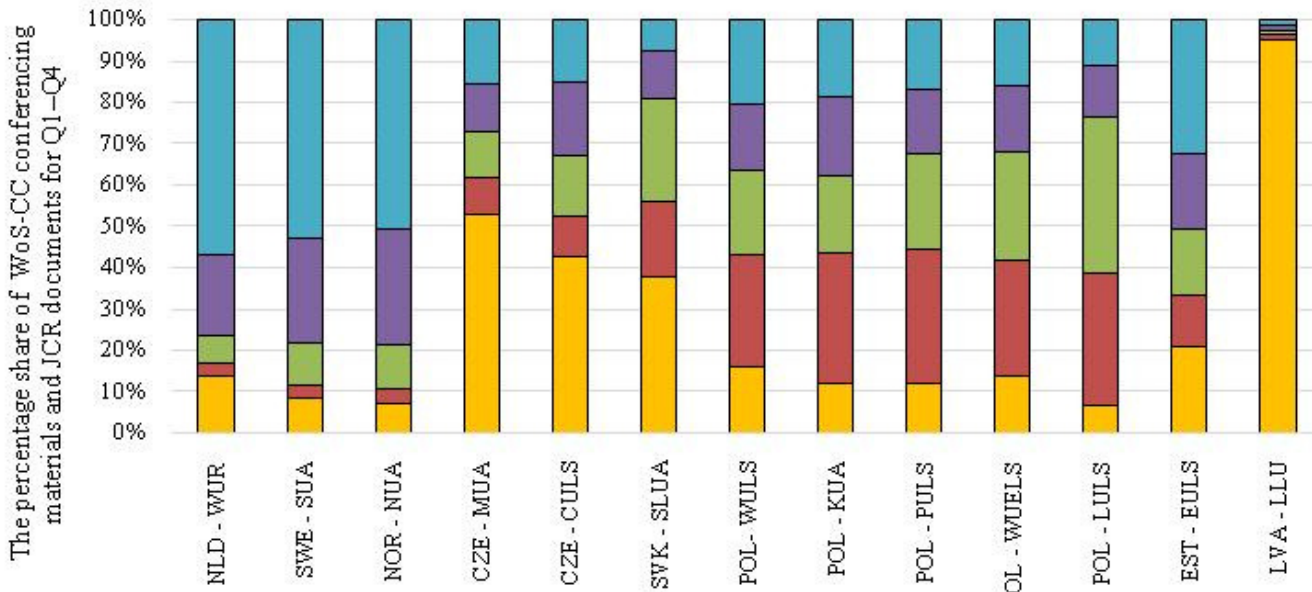

$\square$ WoS-CC $\square \mathrm{Q} 4 \quad \square \mathrm{Q} 3 \quad \square \mathrm{Q} 2 \quad \square \mathrm{Q} 1$

b)
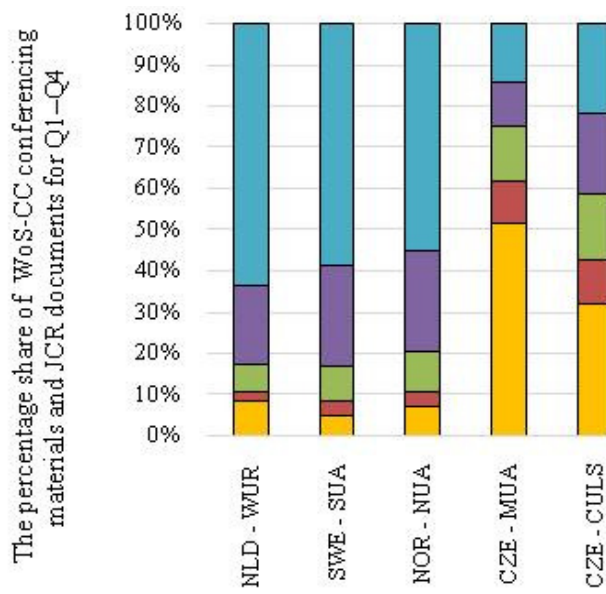

Selected universities

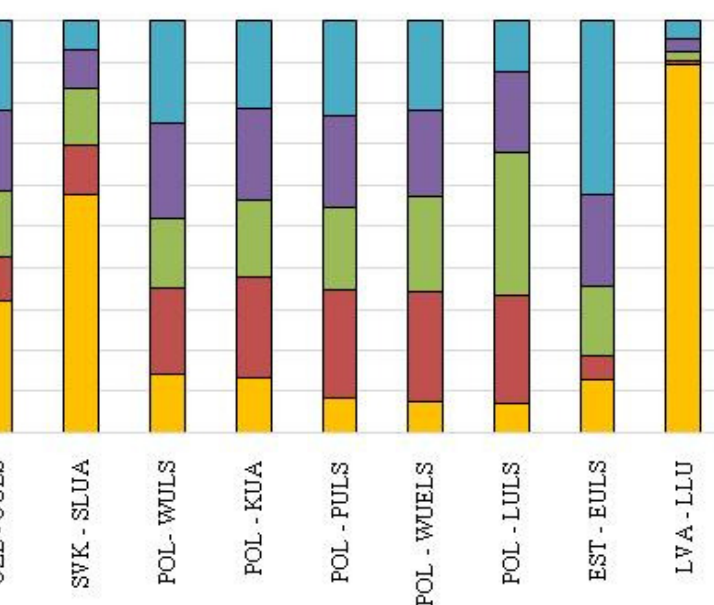

$\square$ WoS-CC $\square \mathrm{Q} 4 \quad \square \mathrm{Q} 3 \quad \square \mathrm{Q} 2 \quad \square \mathrm{Q} 1$

Selected universities

Fig. 5. Percentage share of WoS-CC conferencing materials and JCR documents

for Q1-Q4: a - years 2009-2012 b - years 2012-2016 
There are 5 groups of universities. The first includes universities from the Netherlands, Sweden and Norway - more than $50 \%$ of publications in Q1, over $20 \%$ in Q2, up to $10 \%$ in Q3, up to $5 \%$ Q4 and about $10 \%$ WoS-CC. The second group includes universities from Poland - up to $25 \%$ Q1 and up to $15 \%$ WoS-CC. The third group includes Estonia - the largest number of publications in Q1 (2012-2016 over $40 \%$ ), up to $20 \%$ WoS-CC. Another group are universities from the Czech Republic and Slovakia - the number of publications in Q1 higher for the Czech Republic (15-22\%), both countries above $30 \%$ WoS-CC. The last group includes the Latvian university - about $90 \%$ of publications on WoS-CC.

It can be noted that there has been an increase in the "quality" of publications (increased share of publications in Q1 quartile for all scientific centres). The highest growth was recorded for LVA-LLU from about $1.3 \%$ (2009-2012) to $4.6 \%$ (2013-2016).

Significant differences in the share of the number of publications cited by the JCR in relation to WoS$\mathrm{CC}$ materials between universities in Poland, the Czech Republic, Slovakia and Latvia probably result from differences in the assessment systems of scientific units in individual countries. In Poland, for several years there has been a scoring system in place, in which individual JCR journals are assigned points (15 to 50 points) depending on the position of the respective journals in JCR rankings (between Q1, Q2, Q3, Q4). For example, for publication in Energy \& Fuels [13], an author receives 35 points (2015: Q2 in the ENERGY \& FUELS category; IF - 2,835), and for a publication in the Metrology and Measurement Systems [14], an author receives 20 points (2015: Q3 in the INSTRUMENTS \& INSTRUMENTATION category; IF - 1,140). Post-conferencing materials indexed on the WoS-CC are scored differently. For example, for publications from Renewable Energy Sources: Engineering, Technology, Innovation - ICORES 2017 [15] or 12th International Scientific Conference on Engineering for Rural Development - Proceedings [16], the authors receive 15 points.

\section{Conclusions}

1. An analysis of the number and quality of publications shows that the compared universities can be divided into several classes in terms of their scientific level: Class I - the Netherlands, Sweden, Norway, Class II - Estonia, Class III - Poland, Class IV - the Czech Republic and Slovakia, Class $\mathrm{V}$ - Latvia.

2. In terms of employee publication activity, two groups can be distinguished: I - the Netherlands, Sweden, Norway and the Czech Republic, II - other universities.

3. Division into classes pointed differences in the science development strategy in individual countries and the position of individual scientific institutions depending on the adopted evaluation criterion.

4. For all the analysed universities, both the number of publications and their quality increased over time, which proves the continuous scientific development of employees.

\section{Acknowledgements}

This research was financed by the Ministry of Science and Higher Education of the Republic of Poland (Faculty of Production and Power Engineering, University of Agriculture in Krakow).

\section{References}

[1] Shah M., Nair S., Wilson M. "Quality assurance in Australian higher education: historical and future development,” Asia Pacific Educ. Rev., vol. 12, no. 3, Sep. 2011, pp. 475-483.

[2] Hou A.Y.-C., "Quality assurance at a distance: international accreditation in Taiwan higher education," High. Educ., vol. 61, no. 2, Feb. 2011, pp. 179-191.

[3] Gvaramadze I. "From Quality Assurance to Quality Enhancement in the European Higher Education Area," Eur. J. Educ., vol. 43, no. 4, Dec. 2008, pp. 443-455.

[4] Cret B. "Accreditations as local management tools," High. Educ., vol. 61, no. 4, Apr. 2011, pp. 415-429.

[5] Claassen C. "Measuring university quality," Scientometrics, vol. 104, no. 3, Sep. 2015, pp. 793-807.

[6] Brooks R. "Measuring University Quality," Rev. High. Educ., vol. 29, no. 1, 2005, pp. 1-21. 
[7] Hoecht A. "Quality Assurance in UK Higher Education: Issues of Trust, Control, Professional Autonomy and Accountability," High. Educ., vol. 51, no. 4, , Jun. 2006, pp. 541-563.

[8] Francik S. et al., "Bibliometric Analysis of Multiple Critteria Decision Making in Agriculture," Tech. Sci., vol. 20, no. 1, , 2017, pp. 17-30.

[9] Bojović S., Matić R., Popović Z., Smiljanić M., Stefanović M., Vidaković V. "An overview of forestry journals in the period 2006-2010 as basis for ascertaining research trends," Scientometrics, vol. 98, no. 2, , Feb. 2014, pp. 1331-1346.

[10]Li H., Demeulemeester E. "A genetic algorithm for the robust resource leveling problem," J. Sched., vol. 19, no. 1, , 2016, pp. 43-60.

[11] Wambu E. W., Fu H.-Z., Ho Y.-S. "Characteristics and trends in global tea research: a Science Citation Index Expanded-based analysis," Int. J. Food Sci. Technol., vol. 52, no. 3, Mar. 2017, pp. 644-651.

[12]X. Yaoyang and W. J. Boeing, "Mapping biofuel field: A bibliometric evaluation of research output,” Renew. Sustain. Energy Rev., vol. 28, , Dec. 2013, pp. 82-91.

[13] Kubica K., Jewiarz M., Kubica R., Szlęk A. "Straw Combustion: Pilot and Laboratory Studies on a Straw-Fired Grate Boiler," Energy \& Fuels, vol. 30, no. 6, , Jun. 2016, pp. 4405-4410.

[14] Wójcik A., Niemczewska-Wójcik M., Sładek J. "Assessment of Free-Form Surfaces' Reconstruction Accuracy," Metrol. Meas. Syst., vol. 24, no. 2, Jan. 2017.

[15]Brzychczyk B., Hebda T., Giełżecki J. "Physical and Chemical Properties of Pellets Produced from the Stabilized Fraction of Municipal Sewage Sludge," Springer, Cham, 2018, pp. 613-622.

[16] Lapczynska-Kordon T., Fraczek B., Slipek J., Ivanowa Z. "Genetic Algorithms In Optimisation Of Dried Fruits And Vegetables Quality," in Engineering for Rural Development, 2013, pp. 628-632. 